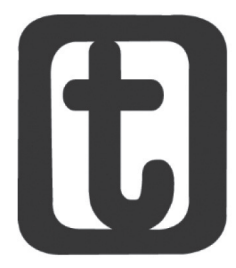

\title{
A QUESTÃO SOCIOAMBIENTAL NA PARTICULARIDADE BRASILEIRA: CARÁTER DESTRUTIVO DA ACUMULAÇÃO CAPITALISTA
}

\author{
The socioenvironmental question in brazilian particularity: \\ destructive character of capitalist accumulation
}

Letícia Soares Nunes*

(cc) BY-NC

\begin{abstract}
RESUMO
Este artigo tem por objetivo discutir as estratégias do capital para minimizar as sequelas da destrutividade socioambiental, centrando esforços nas reflexões em torno da conjuntura brasileira e os graves problemas socioambientais que vem assolando este território, potencializados por uma política ambiental que responde aos interesses do grande capital. Parte-se do pressuposto que tais estratégias são utilizadas como forma de disseminar a ideologia hegemônica de que seria possível compatibilizar sustentabilidade social, ambiental e econômica no capitalismo que, por essência, é destrutivo e desigual. Assim sendo, considerando a pesquisa bibliográfica efetuada na tese de doutoramento, discorre-se neste artigo sobre as contradições do capitalismo que produz de forma ilimitada, mercantiliza a natureza e coisifica o homem, bem como enfatiza-se que a gestão ambiental pública brasileira vem estabelecendo estratégias que estão submetidas à mesma lógica do capital para obtenção de lucro, não interferindo nas causas da crise.
\end{abstract}

\section{PALAVRAS-CHAVE}

Questão socioambiental. Capitalismo. Gestão sociombiental brasileira. Destrutividade.

\footnotetext{
* Assistente Social. Doutoranda do Programa de Pós-Graduação em Serviço Social da Universidade Federal de Santa Catarina (UFSC, Florianópolis, Brasil). (Campus Reitor João David Ferreira Lima, s/n - Trindade, Florianópolis (SC), CEP.: 88040-900). Assistente Social do Serviço de Proteção e Atendimento Especializado a Famílias e Indivíduos (PAEFI) do município de Florianópolis (PMF, Florianópolis, Brasil). (Rua Arnoldo Candido Raulino, 183 - Estreito, Florianópolis (SC), CEP.: $88070-$ 710). E-mail: <leticia_snunes@hotmail.com>.
} 


\begin{abstract}
The objective of this article is to problematize the capital of strategies to minimize the sequels of social-environmental destructiveness, focusing efforts on reflections on the Brazilian situation and the serious social and environmental problems is plaguing this territory, boosted by an environmental policy that responds to the interests of capital. It's assumed that such strategies have been used as a way of disseminating the hegemonic ideology that it would be possible to reconcile social, environmental and economic sustainability within the core of capitalism, which is essentially, destructive and unequal. Therefore, considering the bibliographical research carried out in the doctoral thesis, in this article the discussion is about the contradictions of capitalism that produces in an unlimited way, mercantile nature and objectifies the man, as well as emphasizing that Brazilian public environmental management has been establishing strategies for profit making, not interfering with the causes of the crisis.
\end{abstract}

\title{
KEYWORDS
}

Socioenvironmental issue. Capitalism. Brazilian Environmental Management. Destructiveness.

Submetido em: 20/8/2017

Aceito em: 15/11/2017

\section{INTRODUÇÃO}

Considerando a organização econômica vigente que busca se expandir, produzir e acumular de forma ilimitada, é visível na cena contemporânea uma intensificação da destrutividade socioambiental. Objetivando minimizar o descompasso entre as necessidades de expansão de produção do sistema capitalista e as condições do planeta de sustentar esse estilo de desenvolvimento, principalmente a partir de 1970 o debate da questão socioambiental se tornou mais evidente nas instâncias políticas, na imprensa, nos meios científicos e acadêmicos, movimentos ambientalistas e nos demais segmentos da sociedade.

A partir da referida década realizaram-se conferências, acordos e tratados com o intuito de propor diretrizes de controle da relação sociedade-natureza, influenciando as diretrizes políticas e econômicas dos países periféricos. Assim, pautado pelas orientações dos organismos internacionais, a agenda socioambiental brasileira vem privilegiando o discurso do consumo consciente e das saídas técnicas enquanto principais estratégias para "compatibilizar" produção da riqueza com sustentabilidade social e ambiental no capitalismo. 
Diferentemente desta perspectiva e analisando sob a ótica marxiana, o presente artigo está estruturado na apreensão da questão socioambiental como resultado da acentuação das contradições entre o desenvolvimento das forças produtivas e as relações sociais de produção. Ou seja, atribui-se às relações sociais capitalistas a causa principal da crise socioambiental contemporânea, visto o distanciamento do homem e da natureza, a utilização classista dos recursos naturais e o uso irracional do mundo natural.

\begin{abstract}
Enquanto a produção pré-capitalista de valores de uso tem seu limite na satisfação das necessidades, a produção capitalista de mercadorias para aumentar o lucro não tem nenhum limite. Esta diferença, tão simples e geral, está na base do esgotamento dos recursos naturais a um ritmo nunca suspeitado na história da humanidade; porém também está na base da utilização irracional de qualquer forma de energia e/ou de materiais e seres vivos (FOLADORI, 1997, p. 17).
\end{abstract}

Tal consideração é importante para romper com as perspectivas hegemônicas que justificam que a crise socioambiental está ligada ao desperdício de matéria, aumento populacional, padrão de produção e consumo, pobreza e finitude dos recursos naturais (SILVA, 2008). Sobre esta última, são frequentes os argumentos de que esta crise está relacionada a uma contradição insuperável entre um mundo com recursos finitos e um crescimento infinito da produção. Contudo, Foladori (2001) questiona destacando que se a Terra é finita como lugar de vida e que qualquer espécie tem seu ciclo de vida determinado, assim, o problema não estaria na finitude dos recursos naturais ou das espécies - já que esta é uma característica da vida na Terra -, mas sim da velocidade da sua utilização.

Um segundo argumento está relacionado à utilidade de um recurso, afirmando que este pode ou não ser utilizado, a exemplo do petróleo. Para Foladori (2001, p. 120), “[...] ritmo e utilidade, mostram que os limites físicos ao desenvolvimento humano dizem respeito primeiro a como se produzem e se consomem os recursos, isto é, aos 'limites' humanos, acima dos físicos". Ou seja, o sistema capitalista produz de forma ilimitada, mercantiliza a natureza, coisifica o homem, a fim de obter lucro e não satisfazer as necessidades humanas com a produção de mercadorias. 
Considerando tais pontos de partida e a pesquisa bibliográfica realizada no processo de elaboração da tese de doutoramento, destaca-se que este artigo tem por objetivo discutir as estratégias do capital para minimizar as sequelas da destrutividade, centrando esforços nas reflexões em torno da conjuntura brasileira e os graves problemas socioambientais que vem assolando este território, potencializados por uma política ambiental que responde aos interesses dos grandes especuladores, ruralistas, latifundiários, grileiros, onde o cálculo econômico apresenta um peso maior que a preocupação ambiental e social.

\section{A LÓGICA DESTRUTIVA DA ACUMULAÇÃO CAPITALISTA}

Inicia-se esta seção afirmando que apreender a dinâmica do capitalismo contemporâneo na sua totalidade implica em reconhecer a questão socioambiental enquanto um dos temas medulares da crise capitalista, onde a acentuação da destrutividade socioambiental e a mercantilização dos seus efeitos evidenciam uma contradição crescente própria deste modo de produção. Ou seja, é preciso considerar este binômio em sua estreita relação com as necessidade de expansão da produção e conquista territorial para garantir a acumulação de capital, de um lado, e de outro com as condições do planeta de prover esse desenvolvimento (SILVA, 2008).

Reforçando a conexão existente entre a transformação ecológica e o caráter expansivo do capitalismo, Foster, Clark e York (2010) destacam que:

Uma forma óbvia de mudança de capital em torno de problemas ecológicas é através de deslocamento geográfico simples - uma vez que os recursos estão esgotados em uma região, os capitalistas procuram em todo o mundo para controlar o recurso em outras partes do mundo, seja pela força militar ou pelos mercados. [...]. No entanto, expandir a área sob o controle do capitalismo global é apenas uma das maneiras pelas quais os capitalistas mudam os problemas ecológicos. Há também uma dimensão qualitativa, em que uma crise ambiental é 'resolvida' (tipicamente apenas no curto prazo) alterando o tipo de processo de produção e gerando uma crise diferente, como a mudança do uso de madeira para 
plástico. Na fabricação de muitos bens de consumo substituiu os problemas associados à extração de madeira com os associados à produção e disposição de plásticos. Assim, um problema é transformado em outro - uma mudança no tipo de fenda [...] (FOSTER; CLARK; YORK, 2010, p. 41).

O exposto pelos autores remete para a reflexão de que, desde sua emergência o capitalismo busca novas fronteiras de mercadoria para seguir sua lógica de desenvolvimento. Referindo sobre a acumulação primitiva, Marx (1996) evidenciará que, além de todo o processo de expropriação da produção familiar, artesanal, camponesa que separou o produtor direto dos seus meios de produção e submeteu a atividade agrícola à lógica mercantil, a descoberta e a exploração das colônias propiciaram o enriquecimento de uma parcela da burguesia, sendo importante para o desenvolvimento do capitalismo que estava emergindo.

A descoberta das terras do outro e da prata, na América, o extermínio, a escravização e o enfurnamento da população nativa nas minas, o começo da conquista e pilhagem das Índias Orientais, a transformação da África em um cercado para a caça comercial às peles negras marcam a aurora da era de produção capitalista. Esses processos idílicos são momentos fundamentais da acumulação primitiva (MARX, 1996, p. 370).

Neste sentido, é importante referir que, no quadro da divisão internacional do trabalho, os países periféricos foram/são fornecedores de recursos naturais para os países desenvolvidos, sendo constantemente saqueados na expansão capitalista. Ou seja, a conquista de novos mercados, o caráter predatório em relação à natureza e o emprego de uma mão-de-obra superexplorada, foram os motores da expansão capitalista.

Considerando a lógica de dependência pela qual os países latinoamericanos ou periféricos historicamente estão submetidos, destaca-se o exposto por Ribeiro (1978):

Assim, como se vê, as nações latino-americanas configuram sociedades estruturalmente deformadas porque já nasceram subalternizadas e jamais foram ordenadas para servir seus próprios povos. Primeiro, 
na forma de colônias escravistas destinadas a produzir artigos de exportação para gerar lucros também exportáveis. Depois, na forma de povos nominalmente independentes, mas na verdade atados a estatuto neocolonial de produtores de matérias-primas e gêneros tropicais e consumidores de manufaturas importadas. E, ultimamente, na forma de amplos mercados internos que já justificam a implantação de grandes empresas modernas mas que transferem esta tarefa às coorporações internacionais, convertendo a mesma industrialização em um processo de recolonização (RIBEIRO, 1978, p. 181).

As problematizações realizadas denotam o caráter predatório deste tipo de acumulação, levando Harvey (2013) a designá-lo de “acumulação por espoliação". Neste debate o autor sustenta que as características da acumulação primitiva se mantém ao longo do desenvolvimento capitalista e se aprofundam no capitalismo do século $X X I$, a exemplo do referido anteriormente em relação a mercantilização da terra e expulsão dos camponeses para as cidades e as relações de subordinação econômica e política das nações periféricas.

Demonstrando a conexão entre os processos de urbanização, desenvolvimento e a formação da crise do capital, o autor evidenciará ainda que, além da financeirização, outros mecanismos de valorização de capitais que não apenas a exploração sobre o trabalho e a extração da mais-valia emergem: 1) patenteamento e licenciamento de material genético, do plasma de sementes e produtos que possam ser usados contra as populações; 2) biopirataria e a pilhagem do estoque de recursos genéticos em favor de grandes corporações; 3) depredação dos bens ambientais e a proliferação da degradação; 4) mercantilização das formas culturais de expressão humana; 5) transferência para corporações e privatização de bens até então públicos; 6) mercantilização e privatização dos recursos ambientais e serviços públicos.

Importa ainda sinalizar que os aspectos expostos em relação ao processo de expansão e globalização que remonta, principalmente, finais do século XX, vêm desencadeando graves implicações sociais, econômicas e ambientais, ou, nos termos 
de Marx (1996) intensificando o esgotamento de duas fontes: o trabalhador e a terra.

Em relação ao trabalhador, refere-se que as configurações assumidas pelo mundo do trabalho, evidenciam a intensificação da exploração, através do incremento da produção de mais-valia, no aumento da produção com menor custo; a depressão dos salários abaixo do seu valor; o trabalho precarizado e a polivalência; a criação de um exército de reserva e o desemprego estrutural; a desregulamentação dos direitos conquistados, entre outros. Tais questões também implicam num esgotamento da terra, visto que se verifica, no campo e na cidade, um processo de privatização da terra, concentração fundiária e de segregação socioespacial; uma expansão do agronegócio e produção de commodities que vem trazendo efeitos danosos ao ambiente natural, a exemplo do estabelecimento da monocultura e do uso intenso de agrotóxicos; redução da biodiversidade e intensificação da biopirataria; consumo excessivo e escassez de recursos não renováveis; contaminação do solo e ar, desencadeada, por exemplo, pelas usinas hidrelétricas e mineração; intensificação dos desastres, dentre outras problemáticas que se intensificam no capitalismo e afetam a vida da população mais pauperizada, especialmente, àquelas dos países periféricos.

Ou seja, ainda que a degradação socioambiental sempre existiu nas sociedades humanas, é possível afirmar que as relações sociais capitalistas acirram este processo de destrutividade, haja vista aspectos particulares deste modo de produção. O que se está pontuando é que, diferentemente de modos de produções anteriores, o capitalismo inaugura um sistema de produção cujo objetivo final na produção da mercadoria é a obtenção de lucro e não a satisfação das necessidades humanas, aspecto este que vem revelando a natureza destrutiva deste modo de produção que subordina o valor de uso ao valor de troca e intensifica a exploração dos recursos naturais e do trabalho humano - gerando quebras no equilíbrio metabólico entre homem e natureza, já evidenciado por Marx (1996).

Corrobora-se com Foladori (1999) quando este afirma que:

As relações sociais capitalistas geram tendências de comportamento com o meio ambiente que lhes são particulares. [...] A tendência exclusiva mais geral é 
a produção ilimitada. [...] O crescimento ilimitado da sua produção seria a causa de uma poluição e depredação ilimitadas e segundo alguns autores de uma sobrecapacidade de carga do Planeta. Mas esta tendência ilimitada à produção não é uma conseqüência natural da espécie humana e sim particular da produção capitalista. É claro que a teoria econômica neoclássica e keynesiana têm se encarregado de divulgar o suposto sobre o qual elas se construíram, istoé, que o ser humano tem necessidades ilimitadas. Mas isto jamais foi demonstrado [...]. A tendência à produção ilimitada é o resultado direto e necessário de uma organização econômica que gira em torno da produção de lucro e não da satisfação das necessidades (FOLADORI, 1999, p. 35).

Desta forma, ainda que não se possa desconsiderar que a lógica produtivista e mercantil da civilização capitalista, conduz o planeta a um desastre ecológico de proporções incalculáveis e num ritmo que se acelera, é necessário registrar que não se parte do pressuposto que a crise socioambiental, por si mesma, levará ao "fim" do capitalismo. Tal qual defende Chesnais e Serfati (2003), ainda que o processo de destrutividade seja em algumas situações irreversível, o capital pode pôr em perigo as condições de vida, mas não suas próprias condições de reprodução e de funcionamento, visto que este tem os meios tanto para fazer suportar as consequências dessa destruição “[...] às classes, comunidades e Estados mais fracos, quanto para transformar a "gestão de recursos que se tornaram raros" e a "reparação das degradações" em campos de acumulação (em "mercados") subordinados ou subsidiários” (CHESNAIS; SERFATI, 2003, p. 26).

Portanto, são com estas reflexões que reforçam que o capitalismo gera um emaranhado de contradições ecológicas e, ao mesmo instante, estabelece diferentes estratégias para minimizar a destrutividade e criar condições para manter a acumulação, que se discutirá a conjuntura brasileira na seção a seguir.

\section{AQUESTÃOSOCIOAMBIENTALEAPARTICULARIDADEBRASILEIRA}

Situada a natureza da crise socioambiental e considerando este modo de produção que busca se expandir, produzir e acumular de forma ilimitada, é visível uma intensificação da destrutividade 
ambiental. Afirma-se que o capital se apropria de forma privada da natureza, mediada pelo trabalho humano, e se empenha para atenuar suas manifestações, buscando transformar em possibilidades lucrativas o que poderia constituir em obstáculo (SILVA, 2008; MOTA et al., 2004; CHESNAIS, SERFATI, 2003).

Sejam tais obstáculos de ordem material, como é o caso da escassez de alguns produtos não renováveis, dos custos [...] dos resíduos industriais ou ainda, do comprometimento ambiental provocado pela obsolescência programada do uso das mercadorias. Sejam os obstáculos de ordem jurídico-política, resultantes da pressão dos movimentos sociais envolvidos com a causa ambiental [...] e da regulação pública do uso do meio ambiente, ou ainda, o peso dos obstáculos comerciais, cujas estratégias de competitividade do mercado global que passam a exigir certificações de qualidade [...]. Premido por tais situações, a indústria capitalista, preservando a sua finalidade precípua que é o lucro, desenvolve um conjunto de iniciativas, dentre elas a reciclagem de produtos industrializados ou a chamada gestão empresarial ambiental com o intuito de recriar o processo de produção de mercadorias, redefinindo seus processos produtivos. O faz através do uso de novas tecnologias, da utilização de novos materiais e, principalmente refuncionalizando o consumo da força de trabalho ao criar novos meios de cooperação que dotam a cadeia produtiva de variegadas formas de trabalho. Este movimento responde pelas iniciativas capitalistas para restaurar as bases do processo de acumulação, mobilizando a intervenção do Estado [...] para garantir as condições sócio-políticas e econômicas que viabilizem os processos de mudança [...] (MOTA, et al., 2004, p. 3).

Esses obstáculos convertem-se em estratégias que inflexionaram o discurso e a prática do Estado e empresariado e, corroborando com Mota et al. (2004), Silva (2008) complementará que as iniciativas das empresas capitalistas para auferir lucro perpassam estratégias de gestão ambiental, com ênfase na reciclagem dos resíduos sólidos, nos investimentos em pesquisas, em novas tecnologias e na educação ambiental. 
Sobre os obstáculos materiais, a exemplo da escassez de recursos naturais, Silva (2008) destaca que o capital investe em pesquisas de novas matérias-primas, na recomposição da base de fornecimento em caso de recursos renováveis e alterações nas regras mercantis. No plano econômico, o capital transforma as poluições e a degradação de recursos como água e ar em mercados e novos campos de acumulação e, no plano político, transfere o peso das degradações para os países e classes subalternas, tal qual sinalizado na seção anterior.

Para clarear, faz-se referência a duas correntes das ciências econômicas que não realizam uma crítica à economia de "livre mercado", admitindo que devem ser realizadas medidas de correção para amenizar a destrutividade 1 . A economia ambiental, entende que se um bem transacionado no mercado (insumos, materiais, energia) estiver em escassez, basta elevar seu preço para este ser poupado e substituído por outro abundante. Já os elementos naturais não mercantis como água e ar, devem ser reduzidos à lógica de mercado. Ou seja, a economia ambiental interpreta os problemas socioambientais como externalidades, considerando que o gerenciamento adequado dos recursos naturais seria privatizá-los.

A segunda corrente, economia ecológica, propõe políticas econômicas que busquem a utilização mais eficiente dos recursos ambientais; substituição de recursos não renováveis por renováveis; redução de processos contaminantes. Esta proposição ganha expressão no Desenvolvimento Sustentável e, em face desta estratégia, "[...] a reciclagem de resíduos sólidos e o tratamento dos resíduos industriais passam a configurar como alternativas privilegiadas à escassez de matérias primas e ao comprometimento ambiental provocado pela obsolescência programada" (SILVA, 2008, p. 97).

1 Conforme descrito na sequência, partilham da compreensão da economia ambiental os antropocentristas tecnocentrista que, na análise de Foladori (2005) consiste num grupo que entende que a natureza é externa à sociedade humana e consideram legítima a dominação da natureza pelo homem, realizada fundamentalmente através do desenvolvimento tecnológico. Já os adeptos da economia ecológica, são ecocentristas, visto que reivindicam relações de harmonia com a natureza, defendem a necessidade de frear o crescimento material e populacional por considerar o limite da capacidade dos ecossistemas da terra, bem como a necessidade de utilizar tecnologias "limpas" de pequena escala, compreendendo que estas são benignas para o ambiente. 
Acerca dos obstáculos jurídico-políticos e comerciais, as grandes corporações transnacionais passaram a restringir a ação das empresas que não atendiam às exigências ambientais, tornando o mercado mais seletivo. Se, por um lado, as barreiras ambientais podem significar a incorporação da dimensão ambiental nas transações mercantis, por outro, têm sido instrumento de "proteção velada", permitindo que os países limitem a entrada de produtos em seus territórios sob alegação de descumprimento de normas ambientais, acentuando a competição no mercado e favorecendo os países centrais que, a princípio, dispõe de melhores condições para atender as exigências dos selos verdes e das certificações de qualidade, a exemplo das ISOs 9000 e 9001/2000, 14000 a 14065 (SILVA, 2008).

Nesse processo muitas empresas aderem à responsabilidade socioambiental em função das normas criadas com o intuito de induzir as atividades econômicas a adotarem procedimentos considerados menos agressivos ao ambiente externo. Porém, além dessas normativas e da pressão dos movimentos sociais, a adesão à responsabilidade socioambiental consiste numa estratégia da empresa para se manter na competição do mercado e buscar lucratividade e incentivos fiscais.

Empresas de diversos setores passaram a explorar o marketing dos seus produtos aderindo ao slogan ecológicoe, nesta esfera, visualizase uma ênfase no debate sobre consumo, ficando implícita a ideia de que a solução dos problemas socioambientais seria alcançada quando "cada um fizer sua parte". Portanto, não se questiona a estrutura social vigente e cria-se a falácia de um capitalismo verde, onde a problemática socioambiental é entendida como fruto de um desconhecimento dos princípios ecológicos.

O "consumo consciente" passa a ser compreendido como um componente importante na redução dessas problemáticas e, embora esta seja uma afirmativa verdadeira, destaca-se que as mudanças de posturas não representam muito em termos de redução de danos ambientais se comparadas ao impacto gerado na produção. Ou seja, a ressalva de que o impacto maior está na produção, nas relações de trabalho que aí estão embutidas, no cumprimento ou não às normas ambientais, é necessária para não 
se deslocar a discussão da produção e da esfera pública para a responsabilidade do indivíduo que é um movimento intrínseco do capital, objetivando que o mesmo pense que a responsabilidade começa e termina naquilo que consome (LOUREIRO, 2009).

Seguindo a explanação das estratégias para supostamente "minimizar a destrutividade", é oportuno retomar que, no contexto internacional, a partir de 1970 diversas foram as conferências e protocolos criados para inserir a questão socioambiental na agenda pública. Os documentos resultantes dos eventos ressaltavam discursos de participação, distribuindo as responsabilidades e a superação da degradação à toda humanidade, além de ora responsabilizar a pobreza pela degradação e ora afirmar que o combate à pobreza representava a estratégia para se alcançar a "sustentabilidade". A exemplo do Protocolo de Kyoto em que o direito de poluir virou mercadoria, os acordos efetuados nesses espaços evidenciavam a prevalência do cálculo econômico sobre a preocupação ambiental.

Nacionalmente, sinaliza-se o passado escravocrata e a estrutura latifundiária brasileira, bem como a relação de dependência entre o desenvolvimento do capitalismo no Brasil - e nos demais países da América Latina - e os interesses de expansão econômica dos países capitalistas centrais, conferiram particularidades na forma como os governos brasileiros se posicionavam frente à destrutividade dos recursos naturais (BOURCKHARDT, 2009). Ou seja, enquanto que na década de 1970 internacionalmente a discussão acerca do reconhecimento e enfrentamento dos problemas socioambientais ganhava notoriedade, no Brasil era afastada devido ao auge do modelo desenvolvimentista.

Neste período evidenciou-se um tipo de política econômica que incentivou o crescimento da industrialização. Baseado na exploração dos recursos naturais e na superexploração do trabalhador, as indústrias estrangeiras instaladas nos países subdesenvolvidos já não encontravam mais espaços nos países onde avançava a "consciência ambiental", no entanto, o Brasil as recebia considerando os impactos ambientais do desenvolvimento um "mal necessário", pois interessava o crescimento econômico do país. Discorrendo sobre esta conjuntura, Ferreira (1998) 
sinaliza que a ausência de leis ou normas da política ambiental brasileira, aliada à desvalorização da mão-de-obra no mercado de trabalho mundial "[...] constituíam-se trunfos com os quais o Brasil posiciona-se na geopolítica internacional. [...] Institucionalizar ou dar respostas oficiais [...] pela a melhoria da qualidade ambiental significava [...] abdicar do poder de barganha na ordem econômica internacional" (FERREIRA, 1998, p. 84).

Somente quando a posição brasileira se tornou alvo de críticas internacionais e que passaram a ser estabelecidos limites para concessão de empréstimos junto aos organismos financeiros internacionais é que o Brasil passou a se organizar, embora com muitas limitações, em termos de política ambiental (BOURCKHARDT, 2009). Neste sentido, com base em Cunha e Coelho (2003), destaca-se que foram desenvolvidos três tipos de políticas ambientais: regulatório, estruturador e indutor. As políticas ambientais regulatórias foram centrais de 1930 a 1971, visto a elaboração de legislação para estabelecer normas sobre o uso, apropriação dos recursos naturais e a criação de aparatos institucionais que garantissem o cumprimento da lei. As políticas estruturadoras (1972 a 1987) dizem respeito à intervenção estatal ou Organizações Não Governamentais (ONGs) na proteção ao meio ambiente, a exemplo da criação de áreas de proteção ambiental, Unidades de Conservação. As políticas ambientais indutoras de 1988 até o momento, têm por objetivo influenciar o comportamento dos indivíduos e são implementadas através de linhas de financiamento e políticas fiscais tributárias. Fazse uso de instrumentos econômicos para privilegiar práticas "ambientalmente corretas" e inviabilizar as que resultem em degradação, a exemplo das certificações ambientas.

Ainda que anteriormente à 1980 existissem legislações sobre o tema, a partir da referida década intensificam-se promulgações onde discute-se a utilização racional dos recursos naturais, conservação e preservação da biodiversidade. São exemplos a promulgação da Política Nacional do Meio Ambiente (Lei n 6.938/1981); do Fundo Nacional de Meio Ambiente (Lei $n^{\circ}$ 7.797/1989); da Secretaria Nacional de Meio Ambiente em 1990; do Programa Nacional do Meio Ambiente em 1991; Lei de Crimes Ambientais (Lei n 9605/1998); da Política Nacional de Educação Ambiental (Lei nº 9.795/1999); 
o Estatuto da Cidade (Lei n 10.257/2001); Código Florestal (Lei nº 12.651/2012), entre outras.

Exemplificando retrocessos da agenda ambiental brasileira, além da ofensiva do agronegócio, onde as legislações neste campo têm tentado negar à população o acesso à informação sobre o produto consumido, bem como o Código Florestal que encobriu a redução das Áreas de Proteção Permanentes, relembra-se o desastre ocorrido em 2015 em Mariana (MG) com o rompimento de uma barragem. Conforme Movimento dos Atingidos por Barragens (2015), um estudo encomendado pelo Ministério Público Estadual em 2013 concluiu que havia fragilidades na barragem que poderiam levar ao seu colapso e, a partir deste estudo, demandou da Samarco - de propriedade da Vale e da anglo-australiana BHP Billiton - a construção de um plano de emergência e de alerta que nunca fora realizado. Após o rompimento, foram criadas três comissões parlamentares para investigar as causas do desastre, porém, 13 dos 19 membros das comissões receberam da Vale doações para campanha eleitoral.

Considerando este cenário, a Polícia Federal indiciou a Samarco por crime ambiental, sendo que os governos federal, estaduais e municipais poderiam aplicar sanções caso a empresa não cumprisse o acordo que prevê que a Samarco arque, nos próximos três anos, com $\mathrm{R} \$ 4,4$ bilhões para mitigar os prejuízos causados. Esta questão gerou repúdios, visto que, judicialmente, o poder público e seus órgãos de fiscalização ambiental estariam aceitando o fim do processo que moviam em troca deste acerto entre as partes, reduzindo o poder de fiscalização e coerção. Com a ação civil pública encerrada, ficaria a cargo dos atingidos que se sentiram lesados pelo acordo ingressar com ações, individualizando e fragilizando a população que sofreu com o desastre (RODRIGUES, 2016).

Mediante denúncia do Ministério Público em novembro/2016, 22 pessoas e as empresas Samarco, Vale, BHP Billiton e VogBR tornaram-se réus por crimes ambientais e homicídios desencadeados pelo rompimento da barragem (BERTONI, 2017). Contudo, em agosto/2017 a mídia passou a veicular que a Justiça Federal suspendeu a referida ação criminal e o processo pode vir a ser anulado. 
Ainda em Minas Gerais, 20 dias após o desastre em Mariana, a Assembleia Legislativa do referido Estado aprovou o Projeto de Lei $(P L) n^{\circ} 2.946 / 2015$ que propôs novas diretrizes para licenciamentos ambientais no Estado. Embora a proposta fosse agilizar a regularização ambiental, na realidade, o PL pode reduzir o poder do Conselho Estadual de Política Ambiental, priorizar empreendimentos considerados estratégicos pelo Governo, ampliar a insegurança jurídica, danos ambientais e os conflitos sociais associados a grandes projetos.

Além deste projeto a nível local, quando ainda estava na condição de presidente interino, Michel Temer nomeou para o Ministério da Agricultura o então senador Blairo Maggi - o maior produtor de soja do mundo e, quando governador do Mato Grosso, recebeu o prêmio Motosserra de Ouro do Greenpeace por sua contribuição à destruição da Amazônia - que foi relator de uma Proposta de Emenda Constitucional (PEC) $n^{\circ}$ 65/2012, que estabelece que, a partir da apresentação de um Estudo Impacto Ambiental pelo empreendedor, nenhuma obra poderá ser suspensa ou cancelada, derrubando o licenciamento para obras. Esta PEC segue tramitando no Senado, mas, além dela, outros Projetos (a exemplo do PL do Senado $n^{\circ}$ 654/2015 e PL n 3.729/2004) vêm sendo elaborados, com vistas a desmantelar o sistema de licenciamento ambiental, sendo apelidados como "fábrica de Marianas", considerando o potencial de gerar novos desastres ambientais no país.

Ainda que com resistências, esses e outros projetos seguem tramitando, a exemplo das Medidas Provisórias (MPs) n 759/2016, $756 / 2016$ e 758/2016. A primeira foi sancionada e convertida na Lei $\mathrm{n}^{\circ} 13.465 / 2017$, sendo interpretada como uma anistia à grilagem; a segunda previa alterar os limites do Parque Nacional do Rio Novo, da Floresta Nacional do Jamanxim e criar a Área de Proteção Ambiental do Jamanxim no Pará, sendo vetada em junho/2017, e a terceira que visava alterar os limites do Parque Nacional do Jamanxim e da Área de Proteção do Tapajós, foi transformada em norma jurídica com veto parcial (Lei nº 13.452/2017). Tais ações preveem a redução das Unidades de Conservação, colocam a terra à disposição de grileiros e desmatadores e servem para acomodar grandes invasores de terras. 


\section{temporaliS Nunes, tericla.}

E, ainda que a MP 756/2016 tenha sido vetada, o governo editou o PL $\mathrm{n}^{\circ} 8.107 / 2017$ retomando a proposta de reduzir a Floresta Nacional do Jamanxim e, se na MP a redução era de 305 mil hectares, no PL é de 354 mil. Neste ínterim, ambientalistas acusam Temer de usar a PL e outras medidas como moeda em troca de apoio da bancada ruralista, visto que a Frente Parlamentar da Agropecuária - entidade que representa os interesses do agronegócio - reúne 231 deputados e 25 senadores de diversos partidos, tendo sido fundamental para que a Câmara rejeitasse em agosto e outubro a denúncia contra Temer (WELLE, 2017).

Conforme nota técnica emitida pelas organizações da sociedade civil em repúdio ao $\mathrm{PL}$, dentro dos 354 mil hectares há ocorrência de 312 embargos ambientais e, ao reduzir a proteção de florestas e conceder a possibilidade de regularização fundiária das áreas:

[...] o estado brasileiro desmoraliza ainda
mais a própria política pública de controle do
desmatamento, premiando com terra aqueles que
cometeram crimes ambientais, além de desmoralizar
o próprio governo, que edita um projeto de lei para
atender aos interesses do mesmo grupo que colocou
fogo em caminhonetes do Ibama, vandalizando o
patrimônio público (GT DESMATAMENTO ZERO,
2017, p. 4).

As referidas MP e os PL visam beneficiar os interesses de especuladores e do setor do agronegócio e evidenciam um processo violento de usurpação da terra e de intensificação de conflitos, onde só no primeiro semestre de 2017, 37 pessoas foram mortas, recorde registrado desde 2008 (DANTAS, 2017). Entretanto, agricultores e indígenas não são os únicos atingidos pela violência, a exemplo do referido na citação quando do ocorrido em julho/2017 onde caminhões do Instituto Brasileiro de Meio Ambiente (Ibama) foram incendiados no Pará, bem como em outubro/2017 onde prédios do Ibama e do Instituto Chico Mendes de Biodiversidade (ICMBio) também foram incendiados após uma operação no Amazonas, sendo suspeito dos crimes garimpeiros da região.

Diante do exposto, reitera-se que a expropriação da terra, destrutividade ambiental e ameaça aos direitos humanos no contexto brasileiro não é fato recente, contudo, ainda que com 
os processos de resistência, se agravam quando se vivencia no país um retrocesso do processo democrático e de avanço do conservadorismo, tal qual o que perdurou o ano de 2016 com o desenrolar do impeachment da presidenta Dilma e, consequente posse de Temer e os desencadeamentos desta questão no presente ano. Conforme evidenciado, presencia-se no governo Temer um ataque dos direitos sociais duramente conquistados; desmonte das políticas sociais; diluição das fronteiras entre público e privado, aspectos estes que evidenciam a ênfase em substituir os direitos sociais por direitos econômicos com o discurso de "equilibrar as contas públicas" - questões estas visíveis no Plano "Ponte para o Futuro", na PEC n²41/2016, na Reforma Trabalhista, entre outros. A agilidade na elaboração e busca pela aprovação desses projetos, reforçam a certeza de um golpe orquestrado e da manutenção de um projeto societário que não se pauta nos anseios da população e nem no combate à corrupção. Conforme Löwy (2016):

Citando Hegel, Marx escreveu [...] que os acontecimentos históricos se repetem duas vezes: a primeira como tragédia, a segunda como farsa. Isso se aplica perfeitamente ao Brasil. O golpe de Estado militar de abril de 1964 foi uma tragédia que mergulhou o Brasil em vinte anos de ditadura militar [...]. O golpe de Estado parlamentar de maio de 2016 é uma farsa, um caso tragicômico, em que se vê uma cambada de parlamentares reacionários e notoriamente corruptos derrubar uma presidente democraticamente eleita [...] em nome de 'irregularidades contábeis'. O principal componente dessa aliança de partidos de direita é o bloco parlamentar (não partidário) conhecido como 'a bancada BBB': 'Bala' (deputados ligados à Polícia Militar, aos esquadrões da morte e às milícias privadas), 'Boi' (grandes proprietários de terra, criadores de gado) e 'Bíblia' (neopentecostais integristas, homofóbicos e misóginos) (LÖWY, 2016, p. 96).

Considerando o aprofundamento do conservadorismo, afirmase que as políticas ambientais não são estruturadas de modo a impor limites à forma destrutiva como o capital realiza a produção, havendo, de fato, uma privatização dos lucros e socialização de 


\section{temporälis nunes, Leticia.}

seus prejuízos, convertendo os prejuízos em novas formas de acumulação.

Assim, as principais estratégias engendradas para minimizar as sequelas da destrutividade ambiental perpassam o investimento em alternativas tecnológicas, a busca por responsabilizar o indivíduo pela adoção de hábitos "ambientalmente corretos" e a privatização dos recursos naturais, estando estas amparadas pelo discurso hegemônico de que seria possível compatibilizar desenvolvimento econômico e preservação ambiental no capitalismo. Contudo, entende-se que o próprio desenvolvimento na lógica capitalista é insustentável, sendo impossível pressupor um desenvolvimento sustentável sem superar a desigualdade substantiva, o modo de produção hegemônico e as dificuldades estruturais nele existentes

\section{CONCLUSÃO}

Compreendida a partir da sua radicalidade histórica, a discussão da questão socioambiental descortina o acesso desigual aos bens ambientais e à distribuição também desigual dos efeitos da destruição, e possibilita evidenciar que não há uma crise ecológica em si mesma, mas uma crise capitalista. Embora não se negue que a preservação da natureza é uma estratégia para conter a destrutividade, reafirma-se que não será pela via de pequenas reformas e de mudanças atitudinais que a crise socioambiental será superada.

Partilhado este entendimento, reforça-se que a conjuntura brasileira atual apresenta uma série de desafios. A ofensiva onda reacionária que se intensifica no (des)governo Temer, reforça que as medidas propostas para condução do país são incapazes de responder aos desafios da crise. No âmbito da questão socioambiental, evidenciouse no presente artigo um processo violento de usurpação da terra, de proteção do latifúndio, da propriedade privada, do agronegócio e do capital, de anistia à grilagem, visíveis, por exemplo, quando da referência às Medidas Provisórias e Projetos de Lei que objetivam alterar o processo de licenciamento ambiental, que reduzem as Unidades de Conservação, além da morosidade em relação ao cumprimento das sanções impostas às empresas quando da constatação de crime ambiental. 
Somado a isso, o governo Temer tem realizado "nomeações estratégicas" para determinados órgãos, a exemplo do Ministério da Agricultura, da Funai e do Incra que evidenciam o direcionamento para resguardar os interesses da bancada ruralista, do lobby do agronegócio e das grandes indústrias. Conforme Milanez (2017):

Em poucos dias, o governo de Michel Temer atropelou
direitos indígenas e camponeses e provocou um
pesadelo histórico: nomeou um pastor para a Funai,
indicou um ruralista para o mesmo órgão no Mato
Grosso do Sul e, por fim, indicou um grileiro para o
Incra. [...]. Essas nomeações [...] significam entregar
os direitos de populações vulnerabilizadas justamente
para aqueles que representam o maior risco contra a
sua existência. Essas medidas do golpe que atingem
a reforma agrária e os povos indígenas são, antes de
tudo, cruéis (MILANEZ, 2017, não paginado).

Portanto, nestes tempos de resgate de traços de um passado não muito distante e de agudização das desigualdades e do conservadorismo, é preciso fortalecer as lutas de resistência, buscando alterar os pilares de sustentação do sistema - destrutivo, antissocial - do capital. Faz-se necessário a construção de propostas societárias que vislumbrem redefinir o modo como os seres humanos se relacionam entre si e com o planeta, além de estimular a população a atuar nas questões locais e globais, com o intuito de transformar as relações sociais de exploração e dominação vigentes, construindo um mundo melhor para todos, igualitário, culturalmente diverso e ecologicamente viável.

\section{REFERÊNCIAS}

BOURCKHARDT, V. O capitalismo dependente latino-americano e a apropriação do meio ambiente no caso brasileiro. In: JORNADA INTERNACIONAL DE POLÍTICAS PÚBLICAS, 4., São Luís, 2009. Anais... São Luís, 2009. p. 1-10.

BERTONI, E. Justiça suspende ação que pode punir responsáveis por tragédia de Mariana. El País Brasil, São Paulo, 7 ago. 2017. Disponível em: <https://brasil.elpais.com/brasil/2017/08/07/ politica/1502116923_258608.html>. Acesso em: 8 ago. 2017.

CHESNAIS, F.; SERFATI, C. Ecologia e condições físicas de 
reprodução social: alguns fios condutores marxistas. Crítica Marxista, São Paulo, n. 16, p. 39-75, 2003.

CUNHA, S.; COELHO, M. C. Política e gestão ambiental. In: CUNHA, S.; GUERRA, A. A questão ambiental: diferentes abordagens. Rio de Janeiro: Bertrand, 2003, p. 43-79.

DANTAS, C. Brasil tem recorde de assassinatos em conflitos por terra nos primeiros meses de $\mathbf{2 0 1 7}$, segundo a CPT. G1, São Paulo, 27 maio 2017. Disponível em: <http://g1.globo.com/ politica/noticia/brasil-tem-recorde-de-assassinatos-em-conflitospor-terra-nos-primeiros-meses-de-2017-segundo-a-cpt.ghtml . Acesso em: 30 mai. 2017.

FERREIRA, L. C. A Questão ambiental: sustentabilidade e políticas públicas no Brasil. São Paulo: Boitempo, 1998.

FOLADORI, G. A questão ambiental em Marx. Crítica Marxista, São Paulo, n. 4, p.140-161, 1997.

FOLADORI, G. O capitalismo e a crise ambiental. Raízes, ano 18, n. 19, p. 31-36, 1999.

FOLADORI, G. O metabolismo com a natureza. Crítica Marxista, São Paulo, n. 12, p. 105-117, 2001.

FOLADORI, G. Uma Tipologia del Pelsamiento ambientalista. In: FOLADORI, G.; PIERRI, N. (Org.). Sustentabilidad? Desacuerdos sobre el desarollo suetentable Ciudad del México: . Universidade Autônoma de Zacatecas; Migeul Angel Porrúa, 2005. p. 1-22.

FOSTER, J. B.; CLARK, B.; YORK, R. The Ecological Rift:

Capitalism's War on the Earth. New York: Monthly Review Press, 2010.

GT (Grupo de Trabalho) pelo Desmatamento Zero. Por que o Congresso deve rejeitar projeto que aumentará o desmatamento da Amazônia? Nota técnica de organizações da sociedade civil em repúdio ao PL nº 8.107/2017. São Paulo, 2017. Disponível em: <http://ipam.org.br/wp-content/uploads/2017/07/ Nota-Conjunta-ONGs_PL-Jamanxim_FINAL_26JUL2017.pdf>. Acesso em: 30 ago. 2017.

HARVEY, D. Privatização de tudo gerou protestos, que vão 
continuar pelo mundo, prevê marxista. Folha de São Paulo, São Paulo, 20 de nov. 2013.

LOUREIRO, C. F. B. Mundialização do capital, sustentabilidade democrática e Políticas Públicas: Problematizando os caminhos da educação ambiental. Revista Eletrônica do Mestrado em Educação Ambiental. Rio Grande: FURG, p. 1-11, 2009. Disponível em: <https://www.seer.furg.br/ambeduc/article/view/1134>. Acesso em: 8 de ago. 2017.

LÖWY, M. Brasil: El golpe de Estado. In: GENTILI, P., et al. Golpe en Brasil: genealogía de una farsa. Buenos Aires: CLACSO; UMET, p. 95-98, 2016.

MAB. Tragédia anunciada. Movimento dos Atingidos por Barragens, São Paulo, 7 nov. 2015. Disponível em: <http://www. mabnacional.org.br/noticia/trag-dia-anunciada>. Acesso em: 6 ago. 2016.

MARX, K. O Capital: crítica da economia política: Livro 1. São Paulo: Nova Cultural, 1996.

MILANEZ, F. Na Funai e no Incra, governo aposta em pastores e ruralistas. Carta Capital, São Paulo, 13 jan. 2017.

MOTA, A. E., et al. Capitalismo contemporâneo e meio ambiente: as indústrias de reciclagem, o trabalho dos catadores de lixo e ação do estado. In: SEMINÁRIO LATINOAMERICANO DE ESCUELAS DE TRABAJO SOCIAL, 18., 2004. Anais... San José: ALAETS, 2004. p. 1-11.

RIBEIRO, D. O Dilema da América Latina: estruturas de poder e forças insurgentes. Petrópolis: Vozes, 1978.

RODRIGUES, L. Governos e Samarco firmam hoje acordo para recuperação da Bacia do Rio Doce. Agência Brasil, Brasília (DF), 2 mar. 2016. Disponível em: <http://agenciabrasil.ebc.com.br/ geral/noticia/2016-03/governos-e-samarco-firmam-hoje-acordopara-recuperacao-da-bacia-do-rio-doce>. Acesso em: 2 abr. 2016.

SILVA, M. G. Capitalismo contemporâneo e "questão ambiental": o desenvolvimento sustentável e a ação do serviço social. 2008. 213f. Tese (Doutorado em Serviço Social)Universidade Federal de Pernambuco, Recife, 2008. 
WELLE, D. A floresta como moeda de troca de Temer. Carta Capital, São Paulo, 15 de ago. 2017. Disponível em: <https://www. cartacapital.com.br/politica/a-floresta-como-moeda-de-troca-detemer>. Acesso em: 16 ago./2017. 